\title{
Investigating Sociability and Affective Responses of Elderly Users through Digitally-Mediated Exercises: A Case of the Nintendo Wii
}

\author{
Yin-Leng Theng, Pei Foon Teo, and Phuong Huynh Truc \\ Wee Kim Wee School of Communication and Information \\ Nanyang Technological University, Singappore 637718
}

\begin{abstract}
Worldwide, the growing number of senior citizens is a major source of concern in many countries. Recent developments in digitally mediated games aim to encourage exercise among users. It is generally reported in the wellestablished Technology Acceptance Model (TAM) that users' positive perceptions of ease of use and usefulness with IT systems will be sufficient to predict users' behavioural intention to use the systems. This paper describes a study to explore effects of digitally-mediated exercises such as those in Nintendo Wii on elderly users. We first developed a theoretical model based on TAM linking the antecedents into the key factors using information acquired from an extended literature review. We then undertook a survey of thirty elderly participants at a senior citizens centre in Singapore. Data collection was carried out via a selfreported questionnaire and video observation. Through the use of statistical tests, our findings showed that perceived ease of use and perceived health value were determinants of perceived usefulness. Perceived affective response mediates the influence of perceived usefulness on satisfaction, leading to elderly users' behavioural intention to use. The paper concludes with a discussion on the design and impact of digitally mediated games for elderly users.
\end{abstract}

Keywords: Senior citizens, elderly users, Wii, Technology Acceptance Model, sociability, emotive responses, healthcare, perceived usability, perceived usefulness.

\section{Introduction}

Worldwide, the growing number of senior citizens is a major source of concern in many countries. Recent developments in digitally mediated games (e.g. [11]; etc.) aim to encourage exercise and healthy food consumption among the elderly. Cheok, Lee, Kodagoda, Khoo and Le [2] in the design of inter-generational game for elderly and children demonstrate that exercise is important for both physical as well as mental health. Um [20] claims that regular exercise could reduce anxiety and depression while increasing self-esteem and satisfaction among the elderly. McGuire shows that social interaction between humans is essential for the enjoyment of life [15]. Although Keyani, Hsieh, Mutlu, Easterday, Forlizzi [14] designed a tool that was meant to provide entertainment and exercise for the elderly, the tool also enables positive social engagement. 
Traditionally, digital games have long been considered something for children or young people to be played during their leisure times. Surprisingly, with several new developments in digital games, more games are targeted at elderly users (e.g., [1]; [12]; etc.).

The recently release of the Nintendo Wii games has rapidly become the market leader in gaming since the first launch in November 2006. The proven successful selling record was easily over 20 million units worldwide after a year time. With new interaction devices providing multimodality user experiences, computer games provide active way of engagement with elderly players. Using the WiiRemote, users can experience a greater freedom of body movement than mouse interaction in front of a computer screen. Furthermore, it offers multi-user game experiences with the help of its wireless physical interfaces [13]. This significantly helps to improve the social interaction among the elderly during gameplay.

The Nintendo Wii has created a phenomenon among senior citizens especially those in the United States and Japan to improve health and social interaction among the elderly. The positive implications of playing the Wii seem plenty and they range from improving health of elderly through exercise, to enhancing social interactions among family members and so on. The Wii seems like a fun way for seniors to get some exercise, stimulate their minds, and have a jolly good time. In addition, mental stimulation postpones the onset of dementia and might actually reverse the process. New evidence from the Alzheimer's Society suggests that the progression of Alzheimer's can be slowed by the use of computer-based puzzles. The Wii could also be an ideal toy for the elderly because its controller tracks spatial movement, which allows gameplay with normal human movements.

\section{Case Study: Singapore}

In the recent report on Committee on Ageing Issues by the Ministry of Community Development, Youth and Sports in Singapore (2006) (retrieved on May 22, 2010, http://www.mcys.gov.sg/successful_ageing/report/CAI_report.pdf), it is reported that Singapore will witness an unprecedented profound age shift. The number of residents aged 65 years or older will multiply threefold from current 300,000 to 900,000 in 2030 .

In Singapore, the population is also ageing rapidly. For example, the middle ages of 50 to 59 years old for 2007 have superceded those of 1997 by 50 percent. The study on the local ageing population discussed different issues which faced by the elderly in Singapore, and these issues range from housing, accessibility of amenities such as transportation, affordable healthcare, and active lifestyles. It is also recognised that active ageing will lead to social integration and healthy living among the elderly.

Aging of population was defined as a summary term for shifts in the age distribution of a population toward older ages. It is expected to be the most prominent and significant global demographic trends of the 21 st century [7]. Indeed, it demonstrates several challenges for public health and economic development towards the society. 
Wii has definitely taken off in Unites States especially among the elderly. The responses and reported observations and news in the Internet have made quite a headline that more elderly homes are looking into Wii gaming seriously. In Singapore, a community centre in North Bridge Road has embraced and accepted Wii as a way to create social cohesion for the elderly within the area [6]. Everyday about 30 to 40 elderly residents from the Peace-Connect community center participate or watch elderly play a game of tennis or bowling with the Wii. The article also noted that having fun with Wii has helped to improve the resident's motor skills and hand-eye coordination for about 700 out of the 900 members aged 60 and above.

Based on the success from our European and US counterparts [8], more senior centres are interested to obtain digitally mediated games for the elderly. However, there is little research conducted locally to analyze the significance level of effectiveness and acceptance of these games among elderly in Singapore.

We conducted a pilot study in 2008/9 and found positive results [19]. This paper presents a follow-up study to further investigate the determinants of senior citizens' pre-adoption attitudes towards digitally mediated games for promotion of exercise and health consumption.

An underlying hypothesis of such fitness computer games is that it can be fun for the elderly to play and exercise at the same time; consequently it will improve their physical fitness. In this paper, we describe a second study conducted to examine the impact of digitally-mediated games on sociability and affective responses of elderly gamers in Singapore. Specifically, the main objectives of this paper are:

- To investigate the extent of affective responses and satisfaction of elderly users when using the Nintendo Wii.

- To examine whether the Nintendo Wii provides a platform for sociability for elderly users.

Section 3 describes the theoretical background and research model. Sections 4 and 5 discuss results and findings. Section 6 concludes with implications of game design for elderly users.

\section{The Study}

\subsection{Research Model}

Fishbein and Ajzen [5] developed Theory of Reasoned Action (TRA) Model that defines the connectivity between beliefs, attitudes, norms, intentions and behaviors of individuals in the field of social psychology. Hartwick and Barki [9] explain the role of user participation, involvement, and attitude during system development in IS implementation. Davis [3] continued with the formulation of the Technology Acceptance Model (TAM) to measure the factors that influence the acceptance and adoption of information systems that have integrated into our everyday lives.

TAM, derived from TRA [5, 9], studies the effect of user participation in systems development on IS use. While TRA is a general theory of human behavior, TAM is specific to IS usage. TAM has been proven robust in predicting user acceptance of IT, and has been applied widely in understanding the motivational issues in computer and 
software adoption, as well as usage of information systems [10]. There are various reasons to adopt TAM model as our project research methodology. One of the crucial reasons is because TAM is based on behavioral intention of people, hence it can be useful in determining whether the technology is suitable for the elderly from the psychological perspective. Emotional responses towards the interaction with the technology can be constructive as it has the direct connectivity in terms of usefulness and ease of use. TAM has been proven robust and applied widely in identifying and understanding the motivational issues in term of software adoption and usage of information systems [10].

Based on approach, the model helps to predict the acceptability of an information system; which determined by two main factors: perceived usefulness (PU); and perceived ease of use (PEOU). PU and PEOU are hypothesized to jointly decide users' intention to accept an IT application [3]. The behavioral elements assume that when a person forms an intention to act, one would be free to use it without any limitation.

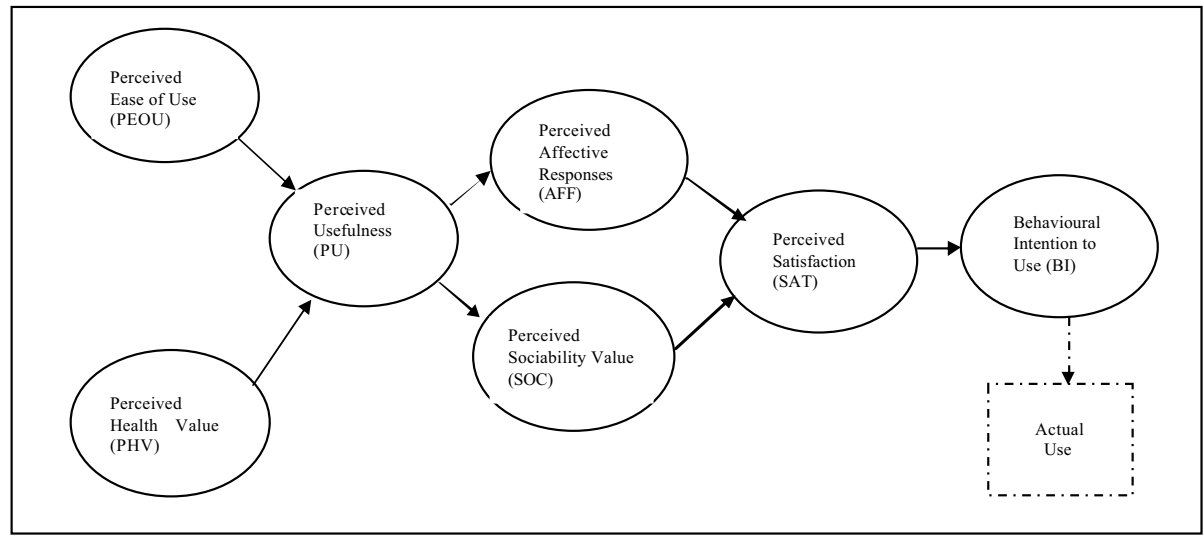

Fig. 1. Research Model

Figure 1 shows our research model adapted from TAM, and the factors explored for this study are as follows:

- $\quad$ Perceived Usefulness (PU) is defined as “the prospective user's subjective probability that using a specific application system will increase his or her job performance within an organizational context" [3].

- $\quad$ Perceived Ease of Use (PEOU) is defined as "the degree to which a person believes that using a particular system would be free of effort" [3].

- Behavioral Intention to Use (BI) is defined as "a measure of the strength of one's intention to perform a specific behavior" [5].

- $\quad$ Perceived Health Value (PHV). Regular physical exercise is always found to be difficult for elderly although it would greatly improve their physical health condition [4]. PHV is the perception of the value of the Wii in promoting exercise and healthy living [20] 
- $\quad$ Perceived Affective Responses (AFF). Affective response refers to the emotional responses perceived by the elderly while interacting with Wii game. This measure is closely related to the satisfaction factor. By investigating the consistency of the emotional responses among the target respondents during the research study, we can simply identify the attitude of elderly when interacting with the Wii game. Measuring this factor is good to evaluate whether a wide range of cognitive issues [17] has been well-considered in designing the Wii games especially for elderly.

- $\quad$ Perceived Sociability Value (SOC). The Wii game offers opportunities for elderly to play with other people, expanding their social circle of friends [8, 15].

- $\quad$ Perceived Satisfaction (SAT). In this measure, we are attempting to understand the satisfaction level of the elderly when integrating with Wii. The satisfaction level towards Wii could reflect directly the pleasure, enjoyment and the actual engagement of Wii game with the elderly. Importantly, it was tailored to examine the satisfaction level which was identified to be significant to increases elderly users' self-confidence, ability to learn, and memo-retention [16]. As it is proven from other studies [18], the increase of self-esteem and life satisfaction has positive influence on mental health of aged people.

\subsection{Measurement Items in the Survey Instrument}

The survey instrument contained measures of the characteristics including health behaviors; emotion and sociability. The constructs employed in the research model was measured using multi-item scales. The survey instrument was formulated to include all the items written in the form of statements with 7-point Likert scales. We conducted a pilot testing of the survey instrument and revisions were made accordingly. Table 1 shows the measurement items (predictor latent construct items) used in the survey instrument.

\subsection{Protocol}

We contacted a few elderly centers to find out if they were interested in the study. The centers contacted were Pertapis, CareCorner, Retired and Senior Volunteer Programme (RSVP) and lastly PeaceConnect. After much deliberation, we concluded that RSVP would the primary centre of interest. RSVP is a non-profit organization focusing on providing community-based services to the elderly, particularly in the areas of education, health, IT and inter-generation integration. Its mission statements are to be a premier entity of active seniors serving and enriching their lives through volunteerism (retrieved on 22 May, 2010, http://www.csv-rsvp.org.uk/site/home.htm).

Similar to most developed countries, in Singapore, chronological age of "65 years and above" is defined as "elderly" or "older persons". This is different from the United Nations (UN) criterion for older population which is someone "60 years and above". Some scientific publications categorize the senior citizens into the "young-old" (aged 65 to 74), "old-old" (aged 75 to 84), and "oldest-old" (85 and over), or "octogenarians" (aged 80-89), "nonagenarians" (aged 90-99), and "centenarians" (over 100), for the purpose of this study, such distinct classification is not relevant. The terms senior citizens, elder( $s)$, elderly, senior(s), aged, and older person(s) would be used interchangeably. 
Table 1. Measurement Items: Predictor Latent Construct Items

\begin{tabular}{|c|c|}
\hline \multicolumn{2}{|c|}{ Perceived Ease of Use (PEOU) } \\
\hline$\overline{\text { PEOU1 }}$ & Learning to Wii is easy for me. \\
\hline PEOU2 & Using Wii would not require a lot of my mental effort. \\
\hline PEOU3 & Overall, I find that Wii is easy to use. \\
\hline \multicolumn{2}{|c|}{ Perceived Health Value (PHV) } \\
\hline PHV1 & Using Wii helps me to avoid tension. \\
\hline PHV2 & Using Wii helps me to stay healthy longer. \\
\hline PHV3 & Using Wii helps me to enjoy life more. \\
\hline PHV4 & Using Wii helps me to stay fit. \\
\hline PHV5 & Using Wii helps me to look younger. \\
\hline \multicolumn{2}{|c|}{ Perceived Usefulness (PU) } \\
\hline PU1 & Using Wii would improve my health \\
\hline PU2 & Using Wii would improve my social interaction. \\
\hline PU3 & Using Wii is a good entertainment option. \\
\hline \multicolumn{2}{|c|}{ Perceived Affective Responses (AFF) } \\
\hline AFF1 & When interacting with Wii, I feel delighted. \\
\hline AFF 2 & When interacting with Wii, I feel happy. \\
\hline AFF 3 & When interacting with Wii, I feel cheerful. \\
\hline AFF 4 & When interacting with Wii, I feel pleased. \\
\hline AFF 5 & When interacting with Wii, I feel eager to play. \\
\hline \multicolumn{2}{|c|}{ Perceived Sociability Value (SOC) } \\
\hline SOC1 & When interacting with Wii, I feel friendly towards others. \\
\hline SOC2 & When interacting with Wii, I feel cooperative towards others. \\
\hline $\mathrm{SOC} 3$ & When interacting with Wii, I feel tolerant towards others. \\
\hline SOC4 & When interacting with Wii, I feel attentive towards others. \\
\hline SOC5 & When interacting with Wii, I feel patient towards others. \\
\hline \multicolumn{2}{|c|}{ Perceived Satisfaction (SAT) } \\
\hline SAT1 & After interacting with Wii, I am interested in Wii, \\
\hline SAT2 & After interacting with Wii, I feel a sense of engagement. \\
\hline SAT3 & After interacting with Wii, I feel a sense of surprise. \\
\hline \multicolumn{2}{|c|}{ Behavioural Intent to Use (BI) } \\
\hline BI1 & I am willing to use Wii to improve my health. \\
\hline $\mathrm{BI} 2$ & I am willing to use Wii to improve my social interaction. \\
\hline $\mathrm{BI} 3$ & I am willing to use Wii for entertainment purpose. \\
\hline
\end{tabular}

However, this study uses "50 years of age or older" as the general definition of senior citizens. Although it was recognized that difficulties may emerge while comparing results with other studies using a different definition of senior citizens, it was deemed necessary to solicit opinions from people in their 50's to gain a wider perspective on both retirees as well as pre-retirees as they are approaching retirement soon and their responses will reflect future needs of senior citizens.

The study was conducted in March 2009. Subjects aged "50 and above" were invited to take part in the study. There were not too many participants in the "above 65 " years old age group at the RSVP centre. The participants at RSVP were paid $\mathrm{S} \$ 10$ for taking part in the 45 -minute session.

First, the participants were instructed to play the different Wii games using the basic set: tennis, bowling, boxing, etc. After 10-15 minutes of interacting with the Wii games, they were then instructed to complete the survey instrument. 


\section{Findings and Analysis}

\subsection{Descriptive Statistics}

Thirty-one participants, aged 50 years and above, took part in the study. Table 2 shows the demographics of the participants. More than $50 \%$ of the participants were above 60 years old. Two-thirds of the participants were females. About $32.3 \%$ of participants went to RSVP three to four times a week and $45.2 \%$ less than 2 times a week, indicating active engagement of these participants with activities at the RSVP.

Table 2. Demographics of Participants

\begin{tabular}{llcc}
\hline \multicolumn{1}{c}{ Demographic variables } & Frequency & \% \\
\hline Gender & Male & 9 & 29.0 \\
Age & Female & 21 & 67.7 \\
& 50 years & 1 & 3.2 \\
& 51-60 years & 13 & 41.9 \\
60-70 years & 14 & 45.2 \\
Education & Above 70 years & 3 & 9.7 \\
& Primary & 3 & 9.7 \\
& Secondary & 19 & 61.3 \\
& Vocational & 3 & 9.7 \\
First Time & Diploma & 3 & 9.7 \\
User of Wii & Degree & 3 & 9.7 \\
Frequency of & First time user & 15 & 48.4 \\
Visit to & Have used Wii before & 16 & 51.6 \\
RSVP & Less than 2 times a week & 14 & 45.2 \\
& 3-4 times a week & 10 & 32.3 \\
& 4-5 times a week & 3 & 9.7 \\
\hline
\end{tabular}

Table 3. Descriptive Statistics

\begin{tabular}{lcccccc}
\hline Construct & Code & $\begin{array}{c}\text { \# of } \\
\text { Indicators }\end{array}$ & Min & Max & Mean & SD \\
\hline Perceived Usefulness & PU & 3 & 4 & 7 & 5.63 & 0.956 \\
Perceived Ease of Use & PEOU & 3 & 2 & 7 & 5.25 & 1.018 \\
Behavioural Intention & BI & 3 & 2 & 7 & 5.45 & 1.185 \\
Perceived Health Value & PHV & 5 & 3 & 7 & 5.45 & 0.973 \\
Perceived Affective Responses & AFF & 5 & 4 & 7 & 5.83 & 0.737 \\
Perceived Sociability Value & SOC & 5 & 4 & 7 & 5.76 & 0.874 \\
Perceived Satisfaction & SAT & 3 & 5 & 7 & 5.78 & 0.737 \\
\hline
\end{tabular}


Of the thirty-one participants, $61.3 \%$ attained secondary school education, confirming our initial observation that this group of elderly was fairly well-educated and able to understand and communicate in English. In terms of Wii awareness, about $51.6 \%$ of participants used Wii at least once.

Means and standard deviations of the model variables are shown in Table 3. On a scale from 1 to 7, from "strongly disagree" to "strongly agree" respectively, the range of means of the constructs ranged from 5.25 to 5.83, all above the "neutral" or middle of the Likert scale. Due to space constraints, we report only some of our findings in this paper.

\subsection{Test of Measurement Model}

Tables 4 and 5 show the reliability and discriminant validity scores of the measurement items. The measurement model links each construct in the theoretical model to indicators of the constructs. In our research model, we were interested in the indicators of the PU and PEOU constructs. The strength of measurement model is determined by conducting convergent and discriminant validity tests of the instrument items.

Table 4. Measurement Model - Reliability

\begin{tabular}{lccc}
\hline \multicolumn{1}{c}{ Variable Constructs } & $\begin{array}{c}\text { Cronbach's } \\
\text { Alpha }\end{array}$ & $\begin{array}{c}\text { The Composite } \\
\text { Reliability } \\
\text { (Internal Consistency } \\
\text { Reliability) }\end{array}$ & $\begin{array}{c}\text { Average Variance } \\
\text { Extracted/Explained } \\
\text { (AVE) }\end{array}$ \\
\hline 1. Perceived Usefulness & 0.9526 & 0.9694 & 0.9136 \\
2. Perceived Ease of Use & 0.8716 & 0.9205 & 0.7945 \\
3. Behavioural Intention to Use & 0.9638 & 0.9764 & 0.9324 \\
4. Perceived Health Value & 0.9633 & 0.9714 & 0.8716 \\
5. Perceived Affective Responses & 0.9859 & 0.9889 & 0.9469 \\
6. Perceived Sociability Value & 0.9751 & 0.9805 & 0.9097 \\
7. Perceived Satisfaction & 0.9807 & 0.9873 & 0.9629 \\
\hline
\end{tabular}

Table 5. Measurement Model - Discriminant Validity

\begin{tabular}{llllllll}
\hline Latent Variables & AFF & BI & PEOU & PHV & PU & SAT & SOC \\
\hline AFF & $\mathbf{0 . 9 7 3 1}$ & 0.0000 & 0.0000 & 0.0000 & 0.0000 & 0.0000 & 0.0000 \\
BI & 0.7254 & $\mathbf{0 . 9 6 5 6}$ & 0.0000 & 0.0000 & 0.0000 & 0.0000 & 0.0000 \\
PEOU & 0.7628 & 0.5593 & $\mathbf{0 . 8 9 1 3}$ & 0.0000 & 0.0000 & 0.0000 & 0.0000 \\
PHV & 0.8450 & 0.6495 & 0.6393 & $\mathbf{0 . 9 1 9 2}$ & 0.0000 & 0.0000 & 0.0000 \\
PU & 0.9117 & 0.6540 & 0.7293 & 0.8809 & $\mathbf{0 . 9 5 4 8}$ & 0.0000 & 0.0000 \\
SAT & 0.9359 & 0.6958 & 0.7202 & 0.7909 & 0.8927 & $\mathbf{0 . 9 6 7 4}$ & 0.0000 \\
SOC & 0.9624 & 0.6955 & 0.7573 & 0.8291 & 0.8913 & 0.9111 & $\mathbf{0 . 9 8 1 0}$ \\
\hline
\end{tabular}

$\mathrm{AFF}=$ perceived affective responses; $\mathrm{BI}=$ behavioural intention; $\mathrm{PEOU}=$ perceived ease of use; $\mathrm{PHV}=$ perceived health value; $\mathrm{PU}=$ perceived usefulness; $\mathrm{SAT}=$ perceived satisfaction; $\mathrm{SOC}=$ perceived social value 
Convergent validity reflects the extent to which the indicators of a construct are similar to the other indicators of the same construct. The convergent validity of each construct was assessed by computing Cronbach's alpha. Cronbach's alpha for the all the constructs were above 0.7 , which is a commonly acceptable level for judging the reliability, indicating that more than $70 \%$ of the variance has been accounted for.

\subsection{Structural Model}

After validating the measurement model, we used SmartPLS to test the structural model. The results of the analysis are depicted in Figure 2.

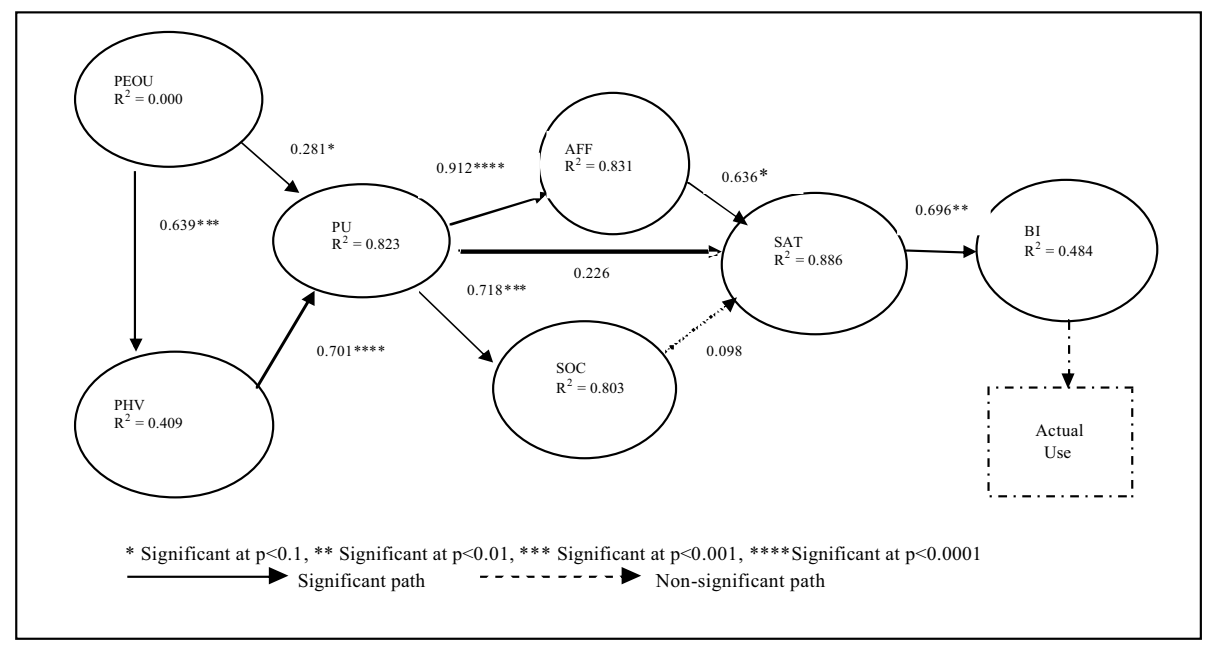

Fig. 2. Research Model Results

Assessing the two antecedents of perceived usefulness, we find that perceptions about the 'perceived ease of use' has a significant relationship with 'perceived usefulness' ( $\mathrm{path}=0.281, \mathrm{t}=2.78, \mathrm{p}<0.1$ ). The relationship between perceptions of 'perceived health value' and 'perceived usefulness' was found to be significant (path $=0.701$, $\mathrm{t}=7.37, \mathrm{p}<0.0001$ ). We also examined the relationship between the 'perceived ease of use' and 'perceived health value' and found a significant positive relationship between the two constructs ( $\mathrm{path}=-0.639, \mathrm{t}=3.82$, $\mathrm{p}<0.001$ ).

The two 'perceived ease of use' antecedents explain $82 \%$ of the variance in 'perceived usefulness'. This suggests the high explanatory power of the theorized antecedents of perceived usefulness, providing empirical validation for the proposed research model.

From the results in the 'consequences' part of the research model, we observe that 'perceived usefulness' in elderly perception has a weak significant relationship with 'perceived satisfaction' (path=0.226, t=1.74). However, the study shows a strong significant relationship between 'perceived usefulness' and 'perceived affective responses' (path=0.912, t=14.13, $\mathrm{p}<0.0001$ ), and a moderate significant relationship between 'perceived affective responses' and 'perceived satisfaction" (path=0.636, 
$\mathrm{t}=2.424, \mathrm{p}<0.1)$. A strong support is also shown specifying a significant relationship between 'perceived usefulness' and 'perceived social value' (path $=0.718, \mathrm{t}=3.708$, $\mathrm{p}<0.001)$. But, there is no significant relationship between 'perceived social value' and 'perceived satisfaction (path=0.098, $\mathrm{t}=0.504$ ). As shown in Figure 2, we observed that 'perceived affective responses' mediate the influence of 'perceived usefulness' on 'perceived satisfaction'.

Next, we observe that 'perceived satisfaction' is a significant predictor of 'behavioral intention' for adopting the Nintendo Wii (path=0.696, $\mathrm{t}=3.268, \mathrm{p}<0.01$ ). Although, Davis [3] argued that ease of use may act indirectly on intentions to use through usefulness, this is indeed an anomalous result and requires deeper investigation to understand the reasons for the differential importance of 'perceived usefulness' and 'perceived ease of use' in the context of the Nintindo Wii providing digitallymediated exercises for elderly users.

\section{Conclusion and On-Going Work}

This study examined the motivations that might influence the intentions of using the Wii among the elderly. Through the use of statistical tests, our findings showed that perceived ease of use and perceived health value were determinants of perceived usefulness. Perceived affective response mediates the influence of perceived usefulness on satisfaction, leading to elderly users' behavioural intention to use. However, there is no significant relationship between perceived social value and perceived satisfaction, implying that perhaps personal enjoyment with Wii is more important than having the opportunities playing with others.

Apart from the entertainment value, the study shows that the Wii games invoked positive affective responses. The involvement with the Wii games could provide alternative ways to keep the elderly active. Although not investigated in this project, the contribution of regular physical exercises through playing Wii games might help elderly stay healthy while stimulating their mental abilities through problem solving and cognitive skills through such gameplay.

Certainly, further studies could be conducted with wider sampling frame and bigger sampling size to achieve greater reliability and generalisability. Future studies could also look at hands-on experiments to identify usability problems encountered by senior citizens when using the Web. Nevertheless, the implications of the study were valuable. Firstly, this is a localised study that looked into the perceptions of senior citizens in Singapore and their perceptions towards digitally mediated games. Secondly, it provided the policy makers and game designers/developers in Singapore a better understanding of the elderly's perceptions and needs, thus narrowing the digital divide in Singapore among the young and old in terms of gameplay. Lastly, it could serve as a reference for future studies for gameplay as applied to the elderly in addressing active ageing.

Acknowledgements. The authors would like to thank the subjects who participated in the study, and Amirrudin Bin Dahlan, Meutia Latifah Akmal, Thant Zin Myint for conducting the pilot study. The project is supported by the Mitsui Sumitomo Insurance Welfare Foundation (MSIWF). 


\section{References}

1. Abdullah Al, M., Omar, M., Suleman, S., Jean-Bernard, M.: Designing and evaluating the tabletop game experience for senior citizens. In: Proceedings of the 5th Nordic Conference on Human-Computer Interaction: Building Bridges, vol. 358, pp. $403-406$ (2008)

2. Cheok, A., Lee, S.P., Kodagoda, S., Khoo, E.K., Le, T.: A Social and Physical InterGenerational Computer Game for the Elderly and Children: Age Invaders. In: Proceedings of the Ninth IEEE International Symposium on Wearable Computers, pp. 202-203 (2005)

3. Davis, F.D.: Perceived Usefulness, Perceived Ease of Use and User Acceptance of InformationTechnology. MIS Quarterly 13, 319-340 (1989)

4. Dishman, R.K.: Exercise adherence: Its impact on public health, pp. 445-447. Human Kinetics Publishers, Champaign (1998)

5. Fishbein, M., Ajzen, I. (eds.): Belief, attitude, intention, and behavior: an introduction to theory and research. Addison-Wesley Pub., Reading (1975)

6. GameFrontz, Wii a hit with elderly residents in Singapore too (May 13, 2008), http: //gamefrontz2.wordpress.com/2008/05/14/wii-a-hit-withelderly-residents-in-singapore-too/ (retrieved August 16, 2008)

7. Gavrilov, L.A., Heuveline, P.: Aging of Population. In: Demeny, P., McNicoll, G. (eds.) The Encyclopedia of Population, vol. 1, pp. 32-37. Macmillan Reference, USA (2003)

8. Geeksugar, Seniors Have Some Swing Batter Batter Wii Fun (August 16, 2007), http: / /www.geeksugar.com/533365 (retrieved August 16, 2008)

9. Hartwick, J., Barki, H.: Explaining the role of user participation in information system use. Management Science 40(4), 440-465 (1994)

10. Igbaria, M., Zinatelli, N., Cragg, P., Cavaye, A.: Personal computing acceptance factors in small firms: a structural equation model. MIS Quarterly 21(3), 279-305 (1997)

11. IJsselsteijn, W.A., de Kort, Y.A.W., Westerink, J., de Jager, M., Bonants, R.: Virtual Fitness: Stimulating Exercise Behaviour through Media Technology. Presence: Teleoperators and Virtual Environments 15(6), 688-698 (2006)

12. IJsselsteijn, W.A., Nap, H.H., de Kort, Y.A.W., Poels, K.: Digital Game Design for Elderly Users. In: Proceedings of Futureplay 2007, pp. 17-22 (2007)

13. Lee, H.J., Kim, H., Gupta, G., Mazalek, A.: WiiArts: Creating collaborative art experience with WiiRemote interaction. In: Proceedings of the 2nd International Conference on Tangible and Embedded Interaction, pp. 33-36 (2008)

14. Keyani, P., Hsieh, G., Mutlu, B., Easterday, M., Forlizzi, J.: DanceAlong: Supporting Positive Social Exchange and Exercise for the Elderly through Dance. In: CHI 2005: ACM Conference on Human Factors in Computing Systems, pp. 1541-1544 (2005)

15. McGuire, F.A.: Improving the quality of life for residents of long term care facilities through video games. Activities, Adaptation \& Aging 6, 1-7 (1984)

16. Ogozalek, V.Z.: A Comparison of the Use of Text and Multimedia Interfaces to Provide Information to the Elderly. In: CHI 1994 Conference Proceedings, Human Factors in Computing Systems, pp. 65-71 (1994)

17. Shneiderman, B.: Universal Usability. Communications of the ACM 43(5), 84-91 (2000)

18. Tad, H., Jodi, F., Elaine, H., Jennifer, G., Jacey, S., Chris, K.: The elder project - social, emotional and environmental factors in the design of eldercare technologies. In: ACM Conference on Universal Usability, pp. 72-79 (2000)

19. Theng, Y.L., Dahlan, A., Akmal, M., Myint, T.: An Exploratory Study on Senior Citizens' Perceptions of the Nintendo Wii: The Case of Singapore. In: Third International Convention on Rehabilitation Engineering and Assistive Technology, Singapore (2009)

20. Um, S.H.: The effect of a regular exercise on mental health on aged people. Science and Technology 3(26), 284-286 (2004) 